\title{
VII. On the alteration of the arcs of vibration of pendulums by the hygrometrical changes of the air; and on a compensating pendulum of deal, applicable to general use
}

\section{Thomas Squire Esq.}

To cite this article: Thomas Squire Esq. (1825) VII. On the alteration of the arcs of vibration of pendulums by the hygrometrical changes of the air; and on a compensating pendulum of deal, applicable to general use , Philosophical Magazine Series 1, 65:321, 38-42, DOI: $10.1080 / 14786442508644653$

To link to this article: http://dx.doi.org/10.1080/14786442508644653

$$
\text { 冓 Published online: } 27 \text { Jul } 2009 .
$$

Submit your article to this journal ए]

$$
\text { Џll Article views: } 2
$$

Q View related articles $\sqsubset$ 


\section{$\left[\begin{array}{ll}38 & ]\end{array}\right.$}

VII. On the Alteration of the Arcs of Vibration of Pendulums by the Hygrometrical Changes of the Air; and on a Compensating Pendulum of Deal, applicable to general Use. By THo. Squire, Esq.

To the Editors of the Philosophical Magazine and Journal.

Gentlemen,

GINCE the time of that eminent mathematician, astrono$\$$ mer and mechanic, Christian Huygens, great improvements have been made in the construction of horological instruments, and especially in those most important parts relating to the clock-I mean the scapement and the pendulum.

It is well known that our atmosphere is often subject to great and sudden vicissitudes with respect to pressure, temperature, dryness and moisture; and these causes, operating in a greater or less degree upon the different parts of the mechanism of the clock, must always have a tendency to render its motion unequal, and for that reason unfit for the purpose of showing the different portions of time with accuracy.

To obviate the effects arising from these different causes, many ingenious contrivances have been adopted.

The variations indicated by the barometer must in some degree affect the arc of vibration, by the changes of buoyancy and resistance; but the error from this source cannot be great, owing to the ponderous materials of which our best pendilums are made, their slow motion, smooth surface, and lenticular form.

On the other hand, the effects arising from the hygrometrical changes of the air do very perceptibly alter the arcs of vibration, they being considerably greater in a moist than in a dry state of the atmosphere; hence, the clock will lose in the former case and gain in the latter. This is a great evil, and $I$ am of opinion that the most perfect jewelling of the pallets will not completely remove it.

In registering several hundred observations of the semi-arcs of vibration made by a clock having a dead scapement, going fusee work, a motive power of 2 pounds, and a pendulum of 12 pounds, I have often found these arcs so variable, though mostly within narrow limits, as to defy calculation, leaving the mind in doubt whether to ascribe the variation in the rate to the arc of oscillation, or an imperfect compensation. The pendulum of this clock is so delicately hung, that a maintaining power at the pallets of no more than $\frac{2}{5}$ of a dram, including the friction of the train, is sufficient to keep it in motion. 
I have also found the variation in the arcs of vibration of a clock with a recoiling scapement, a heavy weight, and a light pendulum, to be still greater than in the one above mentioned, with a dead beat scapement, a light weight, and heavy pendulum.

From these cases it certainly appears reasonable to suppose that the cycloidal checks would be of service, and I see no good reason why they are not now used; as surely a model of so small a portion of the cycloid that would be necessary for the involute arc of vibration, performed by a seconds pendulum, could easily be made. But otherwise, I think Mr. Farnham's plan, of facing the pallets with segments of cylinders, to be the best that has ever been invented, for rendering the arc of vibration constant, provided that under such circumstances a perfect dead beat scapement can be preserved.

I come now to speak of the pendulum simply in itself; and from the nature and importance of this appendage to a clock it requires more than ordinary consideration. Now as it is well known that all metals expand with heat and contract with cold, for this reason the simple pendulum, when constructed wholly of such materials, is found to be useless where great accuracy is required. Accordingly, many ingenious compound pendulums have been invented, for the purpose of counteracting the effects arising from these causes, so that under every degree of atmospheric temperature the centre of oscillation may remain constant. Hence we have the angular, the lever, the conical, the gridiron, the mercurial, and a great many other compound pendulums : but I believe the last two are those mostly used in our best astronomical clocks; and if properly constructed, so that a just compensation is invariably preserved, they must be considered the best of the kind that have ever been invented. Valuable as these pendulums doubtless are in a philosophical point of view, yet they are found to be too expensive for general use. For this reason, I would recommend the wood pendulum in preference to all others, as combining in one important unity, cheapness and utility; and I am moreover convinced from experience, that a pendulum with a deal rod, previously prepared and properly managed, will perform, under similar circumstances, equally well as the best compound pendulum that has ever been invented.

For this purpose take a straight-grained well-seasoned piece of deal, perfectly free from knots, and which in the rough may be about one inch in breadth, half an inch in depth, and three feet and a half in length: let it be exposed for a considerable time to a gradual increasing heat, till at last its surface becomes a little charred; it may, then be planed to its proper breadth 
breadth and thickness; and after cutting it to the required length, let the surface be well coated with copal varnish, and the ends dipped in melted sealing-wax, to prevent the least moisture penetrating the wood, which is of the utmost consequence to the accuracy of the pendulum in its simple state. But still, if, after all, the pendulum should be found to be in some degree affected by the changes of the atmosphere, we happily have in the nature of wood a remedy at hand for this inconvenience.

As the expansion and contraction of deal is much greater across than in the direction of the grain, cut a small block from the waste piece, equal in length to the width of the pendulum rod, and of the same thickness, which may be about .78 of an inch by $\cdot 37$ respectively; let this block be placed with its grain at right angles with that of the rod, having its lower side resting on the nut at the bottom of the pendulum, and its upper side supporting the boh, and which, if judiciously placed behind the front plate, will not only be nearly out of sight, but may be so contrived as equally to compensate for the upper part of the screw, and the small piece of spring on which the pendulum is hung. Experiment proves that with deal the block need not be more than half an inch in width for the compensation of a seconds pendulum rod of the same material.

It is almost unnecessary to remark, that the compensating block should be from a part of the same rod as the pendulum to which it is applied, and also be in every other respect similar as to previous preparation, \&c.

$$
\text { I remain, gentlemen, yours, \&c, }
$$

Epping, Dec. 15, 1824.

Thomas Squire.

P.S. I take this opportunity of returning my best thanks to Dr. Burney and Mr. Veall, for their ready compliance with my request relative to the situation of their meteorological instruments.

I should like very much to see an account of some well conducted experiments on the expansion and contraction of wood, made under different degrees of temperature and dryness, with the ratio of the same across and in the direction of the grain; at the same time pointing out the best and most expeditious methods of entirely destroying this variable property of wood.

T. S.

[We think it may be acceptable to our readers if we subjoin to the above communication with which Mr. Squire has faroured us, some extracts relating to the use of deal for pendulum rods from Mr. Baily's valuable Paper 
on the Mercurial Compensation Pendulum, read May and June 1823 before the Astronomical Society, and just published in the second part of the Society's Memoirs, p. 385, and p. 411.-Ebr'.]

\section{On the Use of Wood for Pendulum Rods. By F. BaILY, Esq.}

"Having enumerated the principal experiments that have been made on the expansion of mercury, I shall proceed to an examination of those which have been made, by various persons, on those substances of which the rod of the pendulum may be composed. Of all these substances, that of wood appears to be the least expansible; but, it is unfortunately so liable to be affected by the moisture of the atmosphere, that, notwithstanding we coat it with varnish, or sealing wax, or paint, or gilding, or even bake it, and impregnate it with oil, it has seldom been found sufficiently accurate for the refined purposes of the modern astronomer. I would not, however, wish to discourage any attempts to render this substance more fit for general use. Fitted up with a leaden bob (in the manner which I shall hereafter describe), it forms the cheapest pendulum that I know of: and, if placed in a room where there is an uniformity in the atmosphere, it might answer every useful purpose for an economical observatory. At all events, it would form an excellent appendage and improvement to the common household clock, and would be far superior to and much cheaper than the usual and absurd mode of hanging a leaden bob to the end of an iron wire.

"I have already stated that an economical pendulum for a seconds clock might be constructed by means of a leaden bob attached to a wooden rod: and I shall now show the mode of determining the relative lengths of these two substances. I have preferred lead to zinc on account of its inferior price, and the ease with which it may be formed into the required shape: and, as there is no considerable difference in their rates of expansion, it is equally applicable to our purpose. If we take the rate of expansion of deal to be 0000022685 , and that of lead to be $\cdot 0000159200$, as given in the table, we shall have $\frac{\xi}{\beta}=\frac{22685}{159200}=\cdot 1425=k$. Now, if we assume the weight of the bob to be 100 times the weight of the rod (which will probably be the case), we shall by means of the equation (D) have $x=2874(1-\cdot 2926+\cdot 3832)=\cdot 313$ : which, being substituted for $x$ in the equation (C), will give $r=45 \cdot 75$ and $b=14 \cdot 90^{*}$.

- If the bob were made of zinc, the length of the cylinder would be only 13.88 inches.

Vol. 65. No. 321. Jan. 1825. 
"This being premised, let us assume $b=14 \frac{1}{3}$ inches, and make the cylinder of any diameter, according to the weight proposed. The construction then of such a pendulum will be as follows. Take a deal rod, of a convenient size, but not less than 46 inches in length, the lower part of which (141 inches long) should be made cylindrical, about $\frac{3}{8}$ of an inch in diameter : or the whole rod may be of this size and shape. Procure a leaden weight or cylinder to be cast, with a hole through the centre which will freely admit the cylindrical end of the rod, and of such a length that when put in the lathe it may be reduced to the required standard of 14.3 inches*, and to the required weight $\dagger$.

"The lower end of the rod should be formed into a screw, to which a wooden nut may be fitted, in order to adjust the pendulum nearly to the given rate: and the final adjustment may be made by means of a slider, as above described $\neq$. A pendulum of this kind will cost but a few shillings, and will answer many useful purposes, as I have found by experience. If the expansion of the rod could be depended on, it would be as accurate as any other. In this construction I have not considered the expansion of that part of the spring which is below the axis of motion. The effect of this may be taken into account, at the final adjustment of the pendulum.

"In all the wooden pendulums which I have seen, the bob has been made of a lenticular shape, and oftentimes been fastened to the rod by means of a pin passed through its centre; and therefore not constructed with any view to compensation. This shape was, I presume, originally adopted with a view to overcome the resistance of the air, and thus reduce the maintaining power of the clock. But it is well known that the air, as a resisting medium, has no sensible effect on the rate of the clock; neither is the rate affected by the shape of the bob; we may therefore choose that shape which will best answer other useful purposes."

* It will be more convenient to have this cylinder too long rather than too short: since we may readily diminish the length of it, if, op trial, it should be found that the pendulum is orer.compensated.

+ The following are the respective weights of a leaden cylinder 14.3 inches long, and having a hole, through the centre, equal to diameter.

$\begin{array}{ccc}\text { Diameter of Cylinder. } & & \text { Weight. } \\ 1 \frac{1}{4} \text { inch. } & = & 6 \cdot 56 \mathrm{lbs} . \\ 1 \frac{1}{2} & = & 9 \cdot 73 \\ 1 \frac{3}{4} & = & 13.47 \\ 2 & = & 17 \cdot 80 \\ 2 \frac{1}{4} & = & 22 \cdot 70\end{array}$

$\ddagger$ A small sliding weight attached to the rod, as described in p. 402 of the Memoirs. 